\title{
Change of lineages relations in villages in the Doi Moi era: Evidence in Vietnam
}

\author{
Dao Thanh Thuy, Hong Duc University, Vietnam \\ Hoang Hong Anh, Hong Duc University, Vietnam
}

\begin{abstract}
The study focuses on analyzing the change of lineages relationship in the village in Dong Son district, Thanh Hoa province, Vietnam from 1986 up to now. To achieve the goal, in this study, we surveyed 101 households living in the study area. The analysis results have shown that 4 main factors are creating the lineage change in the village of Dong Son district, including (i) Changing the lineages relationship from the perspective of the family, (ii) Lineages relations with changes in residence space, (iii) Changing lineages relations in economic activities, mutual assistance, (iv) Changing lineages relations in social life. In which, the most obvious change is the change in the lineages relationship from the perspective of the family after the Doi Moi period. The research results contribute to a study on the lineages relationship in the Doi Moi period through some typical village types in Vietnam.
\end{abstract}

Keywords: Lineages relationship, Dong Son, Village, Change, Vietnam.

Received: 08.12.2020 Accepted: 10.01.2021 $\quad$ Published: 06.02.2021

\section{INTRODUCTION}

In the history of the formation and development of the Vietnamese, the lineages played an important role in the basic principles of social organization in Vietnam. The family line is a kind of universal social organization that dominates individuals in many areas of life. In Vietnam, the lineages have a close relationship with the village community. The lineages are not only a social institution but also a unique cultural environment. Lineage tradition is a factor contributing to the tradition of village communities, localities, and ethnic groups.

The lineages, which crystallize the cultural, material, and spiritual values of the Vietnamese people, play an educational role in the tradition of fondness for learning and the tradition of gratitude to the predecessors. A lineage relationship is a blood relationship that extends beyond the family. In that relationship, each member is allowed to participate in the common family activities, receive mental and material help to a certain extent. At the same time, each person is responsible for building, contributing to the maintenance of the lineage and complying with the general rules set by the lineages. The basic traditional functions of the lineages are shown in controlling marriage, maintaining community cohesion, organizing lineages activities, forming groups of mutual support. With this function, the lineages have long been a link connecting each person in the village community. However, for a long time, the problem of the lineages was more or less negligent, attached to the issue of the clan and the patriarchy.

The Doi Moi process, initiated and led by the Communist Party of Vietnam from 1986 up to now, has been making drastic changes in all aspects of social life. The trend of returning to the roots and reviving the lineage excitingly took place. Especially, from 2010 up to now, the National Target Program on New Rural Construction, approved and put into practice, has created new conditions for the family to develop. Positive aspects of lineages relations are reflected in the building of cultural families, cultural villages, and cultural lifestyles.

As one of the Thanh Hoa cultural sub-regions, Dong Son district has a long history-culture tradition.In the history of formation and development of Thanh Hoa, Dong Son land was selected many times as the place of the district, town and provincial capital. Along with the accretion process of the Chu and Ma rivers, many villages have been formed and developed. Besides the traditional agricultural villages, in Dong Son, there are also some craft villages, which create a diverse economic structure for the village here. Along with economic development, the socio-culture also has many positive changes. In many villages, the lineages relationship changed. And in each type of village, the lineages' relationship has its variation and has its characteristics.

It can be said that the study of the process of rural cultural change based on the changes of the lineages has become an urgent need not only of the sciences but also in the field of state management at all levels. 


\section{LITERATURE REVIEW}

Research on lineages relationship is one of the issues concerned by many domestic and foreign scholars. However, the lineages are rarely studied as an independent issue but are often integrated into the studies of villages, cultural and social changes or the effects of economic change.

Some of the works of foreign scholars on lineages can be mentioned, first of all, the book Les paysans du Delta Tonkinois (Farmer of Tonkin Delta) (Paris, 1936) by P. Gourou [Gourou. P, 2003]. This is a unique work on human geography, the first research on the problems of the Northern rural areas in all fields, including family and lineages.

In 1964, the book "Village in Vietnam" by Hickey was published. This is a basic research work on villages in South Vietnam in the period 1954-1965. The author focuses on Khanh Hau commune on most aspects: formation history, population characteristics, land structure, religious issues, beliefs, lineages and family [Hickey. Gerald. C, 1999].

Research on Vietnamese villages in the 90s of the twentieth century cannot be ignored John Kleinen's work "Facing the Future Reviving the Past: A Study of Social Change in a Northern Vietnamese Village". The book was translated into Vietnamese "Lang Viet doi dien tuong lai hoi sinh qua khu" in 1999 [John Kleinen, 1999]. The book is the result of the author's longstanding attachment to the Vietnamese people. In the previous period, most of the research works focused mainly on the identification of the village structure, that is, the static side of the countryside, the author's research has focused on the dynamic aspect, that is, the changes in Vietnamese society. By the method of anthropological investigation, the author has clarified the variables and immutable factors in village life. The author focuses on factors such as kinship relations, the role of the lineages, power and prestige in the formation of the village's elites, the public field regime, spiritual life and rituals, village autonomy and cohesion. The author has brought suggestions for building appropriate policies for village life.

Studies in Vietnam often focus on analyzing village changes under a macro approach. The implementation of social security policies has a strong impact on the transformation of the cultural, economic - social life of the people. Especially in the agricultural sector, the expansion of industrial zones and urban areas leads to the transformation of land structure, labor structure, changes in social relations, and the process of labor migration [Dao Thanh Thuy and Doan Van Truong, 2020].

In particular, since 2000 onwards, there have been many doctoral dissertations on the lineages, typically: the dissertation on cultural heritage of the lineages and the issue of researching cultural celebrities, developing talents of Vo Hong Hai in 2012 [Vo Hong Hai, 2012]; Lineages relations of the Lung Phan Slinh (research in Cao Loc district, Lang Son province); Lineages relations in Bat Trang pottery village (Bat Trang commune, Gia Lam district, Hanoi city) by Nguyen Thu Hien in 2015 [Nguyen Thu Hien, 2015].

The work "Study promotion and lineages culture in Thanh Hoa" by Nguyen Dinh Manh in 2014 [Nguyen Đinh Manh, 2014] outlines the characteristics of the role of the lineages, their experiences in learning promotion activities and offers some solutions to developing the family's study promotion in the current period.

There are some researchers such as Hoang Anh Nhan, Le Huy Tram, Pham Van Dau, Tran Thi Lien. However, the works of the above scholars focused mainly on the study of village culture in general: Surveying Thanh village culture [Hoang Anh Nhan and Le Huy Tram, 1993]; Village culture and Thanh cultural village [Hoang Anh Nhan, 1996]. The issue of the lineages is mentioned but only for the general introduction.

\section{RESEARCH METHODS}

\section{Sampling method}

We conducted sociological interview surveys in 3 selected research villages. Each village represents some typical village types in Dong Son: agriculture, handicrafts and trade (Nhoi, Nhue Sam and Van Do). Respondents are households belonging to some typical lineages who have lived in Nhoi, Nhue Sam and Van Do villages in Dong Son district from before 1986 to the present. To get a list of people who have lived for more than 30 years in the study areas, we apply for the list at the commune and ward committees. Based on the provided list, we selected a certain number of samples, in which Nhoi village - 44 votes; Nhue Sam - 30 votes and Van Do - 45 votes. After collecting and cleaning the votes, the total number of valid votes was 101, of which Nhoi - 40 votes, Nhue Sam - 21 votes and Van Do - 40 votes. The interview questionnaire consisted mainly of open-ended questions related to issues: the oldest lineages residing in the village, traditional trades of the lineages, death anniversary activities, business family members, paying special attention to the issue of changing lineages relationship in the Doi Moi era. 


\section{Data collection methods}

I. In-depth interviews, we selected interviewees who varied in age, gender, and profession. They are mainly people with high educational background and knowledgeable about the land they live in; cadres who have participated in Party and government work at all levels (province, district, commune, village) and the elderly have experienced two phases before and after 1986; is the head of the clan, the head of the family of three research villages in Dong Son. The content of the interview is prepared with a question system built on the principle of suggestion, from closed questions to open questions so that the respondents can give their opinions.

II. Group discussion, each discussion group usually has 4 to 5 people. Discussion focuses on specific issues such as changes in the lineages relationship in the locality from 1986 to 2016.

\section{RESULTS AND DISCUSSION}

\section{Changing the lineages relationship from the perspective of the family Marriage change}

Previously, marriage in Dong Son villages mainly took place in the village space, where people from the same village married people from the same village. As a pure farming and trading village, the elderly people in Van Do and Nhue Sam villages only marry people from the same village. Particularly Nhoi, due to the specificity of a village with a craft of making stone products, must often go to many places to trade, so since the 1980s, someone married people outside the village and outside the province. However, this number is not much because the concept "I return to me and bathe my pond; Even though the pond is still more chiseled "dominated the thoughts of many young people in the village. Another reason is that their parents, who arranged a marriage for them, still want them to marry people from the same village.

Since the country entered the Doi Moi period, along with the economic changes, the Vietnamese traditional family has also had many changes. The change is reflected in the aspects of marriage, structure, function and relationships in the family.

Regarding marriage, not only the age of marriage has been increased, but the scope of marriage in Dong Son village has also changed. Through surveys of three villages Nhoi, Nhue Sam and Van Do, we show that the marriage space has been expanded and not confined within the village. The above statistics show that the number of households with children marrying someone from the same village accounts for $19.6 \%$; over $50 \%$ in the same district; especially $16.4 \%$ in different districts and $10 \%$ from provinces. The rate of marriage outside the village is mainly in the two villages Nhue Sam and Van Do. Young people in these two villages mainly work away from home, so they mainly marry in different districts and different provinces. This is the cause of the increase in the number of surnames in Dong Son district.

\section{Change the size and structure of the family}

Bearing the common characteristics of the Vietnamese countryside, the traditional families of Dong Son villages stand out with "community character, that is, the members must put the interests of the family first, sacrifice all own benefits if it is contrary to the common interests of the whole family " [Mai Huy Bich, 1993]. Family is at the same time "making many important decisions that directly affect the lives of members, such as decisions about marriage, childbirth, production, consumption, and free time. The family is also a place to educate and orient children social norms related to the behavior of men and women, and through that, convey gender values from generation to generation" [Nguyen Huu Minh, Tran Thi Van Anh, 2009].

In all three research villages, at present, the model of "four generations under the same roof" is no longer popular, only the model of "three generations under the same roof" exists and the nuclear family is dominant. The trend of household separation in the villages of Dong Son took place after 1990 and especially since the career change in the 2000s. There are many reasons for household separation such as economic development in general, housing improvement in particular; the health of the elderly increases, they can live independently; generation differences also affect the separation of households and thus promote family nuclearization [Nguyen Duc Truyen, 2003].

However, the form of the nuclear family is only popular with households working as civil servants or working by office hours. Families that work away from home often choose to live with their grandparents in the style of "three generations under the same roof". From the 2000s onwards, the proportion of workers employed in agriculture decreased, while in non-agricultural sectors increased. Villagers in Dong Son commune have chosen many new jobs to earn extra income. Some choose to work 
near home, but some have to work far away or export labor abroad. Therefore, they choose to live with their grandparents for the convenience of child care and home care.

Thus, the structure and size of the family depend partly on the economic capacity and characteristics of the job. For families with traditional occupations such as Nhoi village, most people want their children to return to take over their parents' work. In contrast, families in agricultural villages like Van Do and Nhue Sam all want their children to have opportunities to find jobs outside.

\section{Household division of labor}

Before 1986, rural women would often stay at home to do housework, take care of their children, which requires endurance and high stamina. This is considered an obvious job of a woman, so it usually does not receive help from men in the family. In addition to housework, the woman also works hard in the fields to produce food for her family.

From 1986 up to now, the division of family labor and the role of women have changed significantly. After the policy of allocating land to households (in 1988), family members can take initiative in production and assign tasks reasonably to bring higher efficiency. With the development of the household economy, the women in the family can do traditional jobs such as taking care of children, housework, and housework while participating in economic production. Their contribution is no less than that of men in the family. Therefore, they not only create income for the family but also promote their abilities that were previously limited. They participate in food production, raise cattle, poultry to create food sources for family life. They are also the main source of income in non-agricultural activities such as trading and services.

It can be said that the woman's role is increasingly confirmed in the family, especially in the household economy. It is a positive change that not only promotes women's abilities but also enhances their status in the family. Even so, the right to decide important tasks remains with the husband.

The man not only plays a decisive role in the important affairs of the family but also in the affairs of the lineages.

Table 1: Ratio of a community work assignment for family members

\begin{tabular}{|c|c|c|c|c|c|}
\hline \multirow[b]{2}{*}{ Type of work } & \multicolumn{5}{|c|}{ Person in charge } \\
\hline & Grandfather & Grandmother & Father & Mother & Children \\
\hline $\begin{array}{lr}\begin{array}{l}\text { Attend } \\
\text { commemoration, } \\
\text { celebrations }\end{array} & \begin{array}{r}\text { weddings, } \\
\text { longevity }\end{array}\end{array}$ & 7.5 & 7.9 & 50 & 33.5 & 1.1 \\
\hline $\begin{array}{l}\text { Attend the work of unions and } \\
\text { authorities }\end{array}$ & 8.5 & 7.5 & 58 & 24.9 & 1.1 \\
\hline Attend the work of the lineages & 9.2 & 73 & 46.6 & 28.1 & 3.4 \\
\hline Attend festivals, temples & 1.2 & 14.0 & 2.7 & 68.9 & 13.2 \\
\hline
\end{tabular}

Source: [Dao Thanh Thuy, 2019]

Although the role of the woman is enhanced, for the outside work, especially the work of the lineages, it is still mainly by men in the family. Women are only allowed to participate when their husbands work away from home, unable to return on thecommemoration of the lineages or clan meetings.

\section{Transforming relationships and family functions}

Change in labor division in the family and income level is the cause of the change in family relationships. In the past, in the villages of Dong Son, the role of members was mainly based on agricultural activities, but now it is gradually replaced by other non-agricultural economic activities. The relationship between wife and husband, between parents and children, has changed.

In the relationship between husband and wife, according to the survey, although the husband is still the main decision-maker, most of them consult with the wife.

The wife not only has a voice but also becomes a "keyholder", adjusting family spending. Especially for households that do business or produce handicraft stones, in all three villages Nhoi, Nhue Sam and Van Do, the role of expenditure coordination is mainly played by the wife.

The gradual approach to equality in the relationship between husband and wife in economic activities is a new signal among non-farm households in Nhoi, Nhue Sam and Van Do. The market economy in the Doi Moi period not only affected the relationship between husband and wife but also 
changed the relationship between parents and children. In the past, parents were the ones who directly took care of and raised children, nowadays, this role is transferred to grandparents or maids. In most families in Nhoi, women often do labor in stone factories. Therefore, taking care of young children mainly depends on grandparents (if they live with their parents), some do not live with their parents and have better economic conditions, they will hire a housekeeper to take care of the children.

Besides, in business households, when the children mature, they will take over the parents' business. According to a survey of 50 businesses in Nhoi, 38 businesses are giving the right to manage again to their children, parents become counselors, coordinate to work together.

When children begin to be economically in charge of the family, it also means that their roles are enhanced. Because they work directly, they have the right to make decisions at work, earn income and gradually participate in family decisions. There is a change in the traditional family order, even in many households the role of children is sometimes greater than that of parents. The conflict stems from the age difference and differences in thinking that stress the parent-child relationship. Although parents give business rights to their children, in reality, they still maintain their power verbally, through important decisions. This is the conflict of many households in the process of transferring power to their children. The head of the family is still nominally the parent, but in reality many families belong to the children.

\section{Lineages relations with a change in residence space}

Dong Son - the western gateway of Thanh Hoa city, often has administrative boundary changes. In the process of expanding Thanh Hoa city, many suburban villages are gradually merged and become a part of Thanh Hoa city. Currently, the image of Dong Son traditional village has been increasingly changed.

Before the 2000s, the big lineages of the three villages Nhoi, Nhue Sam and Van Do such as the Le family, the family name Nguyen and the family name Trinh often lived close together in the village. These are the lineages with a long history of residence in Dong Son land.People of the same family often live close to each other because "the model of marriage in the husband's house is very popular, while newlyweds have little economic ability to establish a household together with difficulties in daily life. That is why relatives are indispensable support." That is the reason why young couple s often live in the same house or close to their parents, cousins. Over time, "kinship residency is a natural and dominant choice" [Mai Van Hai and Phan Dai Doan, 2000].

Income increases, many couples who have accumulated capital have bought land, built houses in newly expanded land areas, next to national highways, next to markets to facilitate business. The land along the surface of Highway 47 through three villages Nhoi, Nhue Sam and Van Do became the residence of many families of different lineages in the village. They are mainly young couples and have a stable income.

According to the survey, from 1986 up to now, in the three research villages, residence space is not only confined to kinship relations but also expanded by neighbor relations. In that s ense, "the space of the lineages relationship is not only the natural space of the blood relation but also the social space: it is social and influenced by social factors" [Mai Van Hai and Phan Dai Doan, 2000].

The process of land structure transformation, area shrinkage and population growth are the reasons why many families' land tends to be split. Modern architecture in house construction has become popular. Not only in Nhoi village - which is affected by the urbanization process, but also in rural villages like Van Do, the imprint of the traditional architectural space is also fading. Some families with economic conditions (especially those with capital from labor export) tend to build according to modern architecture (mainly storey houses, tube houses).

Three-room, two-leaning houses or five-room two-leaned houses only exist in the middle of the village. In the expanded land of the village, the roadside area, the house will be built with a modern design to facilitate living and trading.

The change of the architectural space of the house will be one of the causes leading to changes in family relationships and lineages.

While the architecture of the traditional house attaches to the family members through common activities in the middle of the house, modern house architecture creates private living spaces for the individual. Therefore, relationships between family members tend to be more distant. The lineages relationship is associated with the image of "high walled gates", "everyone's family affairs". In a traditional house, the gate is always open, the fence is just enough to shield the animals from leaving, neighbors can spontaneously visit each other without any specific reason. When there are guests at home, family members chat with them together. In contrast, "the houses with multi-room structure no longer create the maximum for common living space of the family. The rooms are designed to facilitate family members... Everyone in the family only seems to meet during a meal ". 


\section{Change lineages relationship in economic activities, mutual assistance}

The movement of agricultural cooperation has gathered all the land into the cooperative, so the important economic source of the family has disappeared. To replace the benefits obtained from their fields, the members of them seek to contribute to the death anniversary. Since 1986, many localities have replaced the form of death commemoration by setting up a common fund of the lineages. In Nhue Sam and Van Do, due to the main income from agriculture, the method of setting up a fund is to call for voluntary contributions from their members. The per capita contribution is from 50 to 70 thousand VND / person (data in 2016).

In Nhoi district, due to stable economic conditions, they together contribute money to build their lineage hall and build a spacious grave. The lineages activities such as the death anniversary, yearend or year-end meetings or rewarding activities for descendants of Le Van, Le Dinh, and Mai's family are held regularly every year. To maintainthe lineage's activities, each household must contribute to the lineage halla fixed amount each year. Due to the stable economic conditions, the amount of money they contribute is not a burden to the people here.

In the market economy, many new professions have emerged such as real estate business, service business (restaurants, motels, restaurants), machinery repair, especially planting ornamental plants in Nhue Sam and trading stone productsin Nhoi. Up to 2015, Nhoi has 50 households and more than 50 businesses operating in the non-agricultural sectors [People's Committee of An Hoach Ward, 2016].

With the traditional concept "A big fish/a leading light is the crutch of the whole village/area", if there is a head of a business, first of all, their descendants will be employed in the appropriate positions depending on their qualifications. Most companies in Nhoi such as Tan Thanh company, Minh Huong company, Minh Tuan company, Hoang Long, Tan Son are descendants of the company owner.

Meeting the needs of the labor market, in Nhue Sam and Dong Minh, 7 or 8 years ago, the job as a maid became popular and attracted the participation of many people.

The job as a maid mainly attracts women over 40 years old from agricultural villages. They work for families with good conditions and have young children in Nhoi businesses. The appearance of this new profession partly shows the connection between the lineages. Familiarity is the first criterion in choosing the jobs of domestic working women.

\section{Change lineages in social life}

In terms of social life, lineages are considered to share the same ancestral direction, consolidate and promote traditions, commanding descendants to follow. Each member has a common and private social network, has mutual relationships, has a suitable attitude towards personal development and family reinforcement. The family line includes not only people of the previous generation but also people of the same generation, originating from the common ancestor. Families in the same lineage have reciprocity in life, not only with relatives but also with neighbors. Most families borrow from relatives when in need. When a family has important things (housework, marriage, funerals ...), they all seek the support of their relatives.

However, there is always competition between members of finance, degrees, and careers for values that cannot be measured such as success and individual happiness. This competition is evident through home anniversaries or any occasion, especially an economic comparison. Instead of harsh criticism, they only give examples and evidence to strive to build a better family. That is the positive opinion of members in most lineages in Dong Son, the lineage does not want to break good bonds, keep the peace within the clan. However, in our opinion, pointing out the negative points and giving them feedback will make them correct their mistakes, which in turn motivates the family to develop. Almost every problem that arises is also resolved internally, which underlines the importance of its seniors. They still have the power and authority to command their children and grandchildren.

\section{CONCLUSIONS}

The process of urbanization and market economic relations have affected the family-lineages relationship in Dong Son. In that transformation, many good traditions disappeared, relationships were somewhat lax, less strong. In addition, some basic traditional values of families and lineages have also been revived and restored. The economy improves, members of each family have conditions to care for each other more and participate in community activities more actively. Comparing the strength of these relationships, the purely agricultural villages such as Van Do or Nhue Sam are more solid than those in Nhoi village - a handicraft and service village, strongly influenced by the urbanization. 
In general, in all three research villages, the lineages relationship, even though there are some changes, is still limited to the function of sympathy, expressed in helping, sharing joy or condolence. Economic assistance among the members is limited. In terms of appearance, lineages and lineages relations have had many positive changes. However, looking inside, there are still many conflicting opinions. Under the eyes of some people who go to settle down to the village, the clan tends to recover; while for many old people living in the village, the kinship relationship is more and more looser and fading. Because they rely on the fact that the young generation - the successors are "struggling" with the needs of livelihoods, setting up a career in many different places and only appear at the beginning of the year or the end of the year.

Therefore, it can be seen that the change of lineages and lineages relationship in any direction sometimes depends on the perspective and perceptions of each person.

\section{REFERENCES}

Mai Huy Bich (1993), Family Characteristics of the Red River Delta, Culture Publishing House, Hanoi.

Gourou. P (2003), Farmer in the Bac Ky Delta, Youth Publishing House, Ho Chi Minh City.

Mai Van Hai, Phan Dai Doan (2000), Lineages relations in the Red River Delta, Social Science Publishing House, Hanoi.

Vo Hong Hai (2012), Cultural heritage of the lineages and the issue of researching cultural celebrity, current talent development, Doctoral thesis in Cultural Management, Vietnam National Institute of Culture and Arts.

Hickey. Gerald. C (1999), Village in Vietnam, Newhaven Yale University Press.

Nguyen Thu Hien (2015), Lineages relations in Bat Trang pottery village (Bat Trang commune, Gia Lam district, Hanoi city) tradition and change, Doctoral thesis of Anthropology, Academy of Social Sciences.

John Kleinen (1999), Facing the Future, Reviving the Past: A Study of Social Change in a Northern Vietnamese Village, Institute of Southeast Asian Studies.

Nguyen Dinh Manh (2014), Study promotion and lineages culture in Thanh Hoa, Literature Publishing House, Hanoi

Nguyen Huu Minh, Tran Thi Van Anh (2009), Family and gender studies in the Doi Moi period, Social Sciences Publishing House, Hanoi.

Hoang Anh Nhan (1996), Village culture and cultural village of Thanh Hoa, Social Science Publishing House, Hanoi.

Hoang Anh Nhan, Le Huy Tram (2014), Traditional festivals of Thanh origin, Culture and Information Publishing House, Hanoi.

Dao Thanh Thuy (2019), Economic and social transformation of villages in Dong Son region, Thanh Hoa province from 1986 up to now, Ph.D. thesis in Vietnam studies, Hanoi.

Dao Thanh Thuy, Doan Van Truong (2020), Factors Affecting the Socio-Economic Change of Vietnamese Communes From 1986 to The Present: A Household-Level Study, Revista Argentina de Clínica Psicológica, Vol. XXIX, N 3, 292-298, DOI: 10.24205 / 03276716.2020 .722$.

Nguyen Duc Truyen (2003), Household economics and social relations in rural areas in the Red River Delta during the Doi Moi period, Social Science Publishing House, Hanoi.

People's Committee of An Hoach Ward (2016), Summary Report on the socio-economic situation of An Hoach ward, Thanh Hoa city, 2016, kept at the People's Committee of An Hoach ward, Thanh Hoa city. 